\title{
A prática do estágio na formação docente: um olhar sobre a experiência vivida no CAp - COLUNI/UFV no contexto presencial e remoto, durante a pandemia da COVID-19
}

\author{
The practice of internship in teacher education: a look at the experience lived at CAP \\ - COLUNI / UFV in classroom lesson and remote context, during the COVID-19 \\ pandemic
}

\section{Geisevânia da Silva Martins ${ }^{1}$; Marco Túlio C. S. Moreira ${ }^{2}$; Maik Taylor da Silva ${ }^{3}$; Yann N. Mateus Costa ${ }^{4}$, Leomar Tiradentes ${ }^{5}$.}

\begin{abstract}
RESUMO: O estágio é uma forma de aprendizado e como tal, deve ser feito visando preparar o licenciando para lidar com os desafios da carreira docente. A abordagem teórica utilizada fundamenta-se em autores acerca do tema, (Bondía (2002), Manfredi (1996), Scalabrin e Molinari (2013), etc.) e na descrição da trajetória do estágio, onde busca-se num relato de experiência, compartilhar vivências e momentos cotidianos de quatro estagiários do curso de licenciatura em Geografia da Universidade Federal de Viçosa (UFV). O estágio ocorreu no Colégio de Aplicação (CAp/COLUNI) da UFV no primeiro semestre de 2020. O objetivo é descrever o contato direto, pela primeira vez, com uma sala de aula e as vivências com o ambiente escolar, seus espaços e também com os docentes, discentes e demais profissionais da escola. Aponta-se também, as mudanças que ocorreram devido à pandemia da COVID-19, fazendo com que o estágio passasse a ser executado, depois de alguns meses paralisados, de forma completamente remota via tecnologias digitais e online. Por fim, faz-se uma diferenciação entre a modalidade presencial e remota, destacando os pontos positivos e negativos que acompanharam essa mudança.
\end{abstract}

PALAVRAS-CHAVE: Ensino de Geografia; COVID-19; Estágio Acadêmico.

\begin{abstract}
The internship is a form of learning, such, it must be done aiming to prepare the licensee to deal with the challenges of the teaching career. The theoretical approach used is based on authors on the theme, (Bondía (2002), Manfredi (1996), Scalabrin and Molinari (2013), etc.) and on the description of the trajectory of the internship, where an experience report is sought to share experiences and everyday moments of four interns from the Geography degree course at the Federal University of Viçosa (UFV). The internship took place at the College of Application (CAp / COLUNI) of UFV in the first semester of 2020. The objective is to describe the direct contact, for the first time, with a classroom and the experiences with the school environment, its spaces and also with teachers, students and other school professionals. It also points out the changes that occurred due to the pandemic of COVID-19, causing the internship to be executed, after a few months paralyzed, completely remotely in a digital and online way. Finally, a differentiation is made

\footnotetext{
${ }^{1}$ Acadêmica do curso de licenciatura em Geografia da Universidade Federal de Viçosa. ORCID: https://orcid.org/00000002-3101-33791. E-mail: geisev.1998@gmail.com

2 Acadêmico do curso de licenciatura em Geografia da Universidade Federal de Viçosa. ORCID: https://orcid.org/0000-0001-9333-420X. E-mail: marcotcsm97@ gmail.com

${ }^{3}$ Acadêmico do curso de licenciatura em Geografia da Universidade Federal de Viçosa. ORCID: https://orcid.org/00000001-9558-2581. E-mail: maiktaylo2020@gmail.com

4 Acadêmico do curso de licenciatura em Geografia da Universidade Federal de Viçosa. ORCID: https://orcid.org/0000-0003-4204-5840. E-mail:yannxaneis@ hotmail.com

5 Professor Doutor em Geografia, lotado no CAP/COLUNI e orientador do estágio acadêmico. ORCID: https://orcid.org/0000-0002-7258-7926. E-mail: leotiradentes@ufv.br
} 
between the face-to-face and remote modality, highlighting the positive and negative points that accompanied this change.

KEYWORD: Teaching of Geography; COVID-19; Academic Internship.

\section{O COLÉGIO DE APLICAÇÃO DA UFV}

O colégio em análise foi criado em 26 de março de 1965, pelo Conselho Universitário da antiga Universidade Rural de Minas Gerais (UREMG), com a denominação de Colégio Universitário (COLUNI). Ele surgiu para atender a uma demanda específica da UREMG, e foi implementado como Colégio Universitário, no qual funcionava apenas a terceira série, com função preparatória para o vestibular.

Na década de 1980, a Reitoria da Universidade Federal de Viçosa (UFV) nomeou uma Comissão de professores do Departamento de Educação para apreciar a situação de funcionamento do COLUNI. Assim, foi proposto a sua transformação em Colégio de Ensino Médio, além da criação de uma matriz curricular que atendesse às exigências da legislação vigente. Em meados da década de 1990, iniciou-se a discussão que resultou no projeto de transformação do COLUNI em Colégio de Aplicação e somente no ano de 2001, foi criado o CAp-COLUNI, pelo Conselho de Ensino, Pesquisa e Extensão (CEPE/UFV).

O CAp-COLUNI, órgão da UFV, subordinado a Pró-Reitoria de Ensino, destina-se à formação do aluno exclusivamente para o ensino médio. No decorrer de sua história, o colégio tornou-se referência em ensino público de qualidade e ainda mantém a tradição de ser o melhor de Minas Gerais e um dos mais conceituados do Brasil, segundo dados divulgados pelo Instituto Nacional de Estudos e Pesquisas Educacionais Anísio Teixeira (INEP) e publicados pela Folha de São Paulo (FOLHA DE S. PAULO, 2019).

Com um quadro de professores qualificados ${ }^{6}$, trabalhando em regime de dedicação exclusiva, o que permite maior atendimento às dificuldades individuais dos educandos, capacitando-os para a aplicação de seus conhecimentos em situações diversas, o corpo docente se mostra estritamente envolvido na busca de uma prática educacional mais eficiente e comprometido com a realidade do país.

O colégio destaca-se por ser uma comunidade aberta ao diálogo, portanto, os estudantes participam ativamente de todo o processo educacional e pedagógico. Esta é uma condição imprescindível para o desenvolvimento integral dos discentes. As atividades de ensino do colégio desenvolvem-se em modernas instalações no campus UFV/VIÇOSA. Convém ressaltar que os

\footnotetext{
${ }^{6} \mathrm{Na}$ atualidade, o corpo docente do CAp-COLUNI apresenta um total de trinta e três professores efetivos, sendo nove mestres e vinte e quatro doutores em suas respectivas áreas de atuação (COLUNI, 2021).
} 
estudantes utilizam, ainda, a Biblioteca Central, a estrutura do Departamento de Educação Física, os restaurantes universitários, os museus, os espaços de lazer, entre outros locais do campus, favorecendo um amplo convívio com os espaços e as práticas acadêmicas.

As principais motivações nas quais nos fizeram escolher o CAp-COLUNI como campo da prática docente, giraram em torno dessa excelência de seu ensino e por ser uma escola de referência na região, o que nos possibilitaria um maior benefício em nossa formação acadêmica.

É válido ressaltar que este relato de experiência tem por objetivo identificar às experiências de quatro estagiários de Geografia, que vivenciaram o primeiro contato direto com a sala de aula, transitando do ensino presencial para o ensino remoto num contexto de pandemia.

\section{METODOLOGIAS DE ENSINO-APRENDIZAGEM DO CAP-COLUNI}

Metodologia de ensino é a principal forma de delinear um caminho em busca de atingir um determinado objetivo no processo de ensino-aprendizagem, e com isso, construir uma relação dialógica em que os envolvidos no processo, estejam inseridos na construção de conhecimento. Nessa perspectiva, Cavalcanti (2011) disserta em sua obra "Ensinar Geografia para a Autonomia do Pensamento: o desafio de superar dualismos pelo pensamento teórico crítico", sobre como a prática de ensino tem como principal papel viabilizar o desenvolvimento mental dos alunos, construir conhecimentos que ajudarão a formar uma compreensão significativa da realidade. Tendo compreendido melhor o papel das sistematizações do ensino e sua importância, partimos para nossas vivências como estagiários iniciantes no CAp-COLUNI e o que observamos nos métodos utilizadas pelo colégio.

Durante o período do estágio, observamos que, no cotidiano da escola, o relacionamento entre os docentes e discentes é marcado pela horizontalidade dos saberes. Prova disso, são as dinâmicas elaboradas pelo professor nas quais os alunos se organizavam em grupos na sala de aula para fazerem reflexões sobre as temáticas propostas. Tal prática é importante porque confere aos estudantes um grau maior de liberdade para que construam conjuntamente o conhecimento, despertando a sensibilidade dos jovens para que aprendam a lidar com diferentes opiniões acerca de um determinado assunto e, além disso, realçar valores humanos essenciais, como empatia, solidariedade, compaixão e resiliência, fundamentais para o crescimento individual e o bem-estar coletivo.

O modelo de ensino que o colégio propõe dialoga em certos aspectos com a teoria idealizada pelo educador brasileiro Paulo Freire. Em seu livro "Política e Educação" Freire (1992), ele defende que a educação deve ser vista como um ato político capaz de despertar um olhar crítico para que, consequentemente, seja capaz de possibilitar o exercício da cidadania. Desse modo, educar é um 
processo dinâmico, a partir do qual se expressa uma visão sobre o mundo e os sujeitos. As situações vivenciadas por nós no estágio corroboram essa relação, pois a infraestrutura da escola bem como as metodologias adotadas para a interatividade social e para a formação reflexiva dos estudantes.

Nesse sentido, de modo a exemplificar os argumentos citados, podemos destacar a "Quinta Cultural”. Essa foi uma atividade semanal promovida pelo Grêmio Estudantil do colégio, direcionada aos discentes. $\mathrm{O}$ projeto tem como finalidade estimular e inserir os sujeitos às múltiplas atividades artísticas, como, por exemplo, espetáculos de danças, músicas e leitura de poemas autorais. Essa dinâmica permite que a subjetividade e autonomia dos alunos sejam potencializadas, tais características, no que lhe concerne, geram confiança bem como enriquecimento cultural dos mesmos.

Esses projetos desenvolvidos pela escola mostram como uma metodologia de ensino que baseada em princípios capazes de instigar a procura pela diversidade cultural de nosso país pode ser benéfica, tendo em vista que, a partir disso, é possível formar cidadãos críticos, capazes de desenvolver e exercitar sua criatividade.

O evento "Quinta Cultural" foi uma experiência que podemos apreciar. Porém, o colégio conta com diversos outros projetos acadêmicos, que desenvolvem diversas atividades extracurriculares. Os projetos conseguem possibilitar a organização de conhecimentos dos alunos, além de incentivar a pesquisa, reunindo e fazendo relação com diversas áreas de estudos. Esses projetos envolvem as mais variadas atividades, por exemplo, trilhas, feiras culturais, concursos musicais, jogos intercalasses entre outros.

Outra atividade extraclasse que podemos destacar é uma viagem de campo promovida pelos professores de Geografia e História à cidade de Ouro Preto (MG) com os estudantes. Essas aulas foram planejadas a fim de possibilitar uma maior interação entre teoria e prática. A prática em campo é uma grande oportunidade para que os mesmos registrem, observem e descubram novos ambientes fora do âmbito escolar. Essas atividades interdisciplinares são capazes de sensibilizá-los diretamente para a relação sociedade/natureza, por isso, essa abordagem metodológica do ensino pode auxiliar o aluno a ressignificar os conteúdos a partir das vivências.

Os projetos desenvolvidos pela comunidade escolar do CAp-COLUNI, mostram como é importante a valorização e a luta pela educação pública, laica, socialmente referenciada e de qualidade em nosso país. Além disso, é essencial, adotar boas metodologias de ensino, que visem a autorrealização de todos, pois todos esses aspectos estimulam o respeito mútuo e a boa comunicação entre os membros da comunidade escolar. 


\section{A PRÁtICA PEDAGógICA OBSERVADA NO PROCESSO DE FORMAÇÃO INTEGRAL}

É inegável que a experiência do estágio escolar configura-se como uma etapa fundamental no processo de formação educacional dos licenciandos, sendo em muitos casos um instrumento pedagógico crucial para decisão de prosseguir ou não com o sonho de ser professor(a). Nesse sentido, como sujeitos transitórios no espaço do CAp-COLUNI, tivemos uma oportunidade ímpar de ampliar a nossa compreensão em relação ao processo de ensino-aprendizagem.

Baseando-se em nossas curiosidades sobre a prática educacional, buscamos, neste trabalho, refletir sobre dois questionamentos: qual o papel dos docentes na trajetória escolar do aluno? De que forma os professores atuam para assegurar que seus educandos obtenham uma formação efetivamente transformadora, e que seja capaz de prepará-los para intervir de forma a alterar o cenário social no qual estão inseridos?

As respostas para esses questionamentos vieram a partir de uma observação crítica no que se refere ao modo como os temas propostos são trabalhados na sala de aula. Em primeiro lugar o que nos chamou atenção foi a relação entre professor e estudantes no colégio. Percebemos de imediato que o clima das aulas era leve e descontraído. Além disso, o professor tinha plena convicção de que seu papel não deve ser o de alguém que simplesmente repassa, de forma trivial, seu conhecimento com o intuito de receber reconhecimento e ganhos salariais ao final do mês. Isso se justifica, porque está evidente sua preocupação com o bem-estar do alunado. Neste sentido, Leite; Tassoni (2006), destacam que:

[...] as relações de mediações feitas pelo professor, durante as atividades pedagógicas, devem ser sempre permeadas por sentimentos de acolhida, simpatia, respeito e apreciação, além de compreensão, aceitação e a valorização do outro; tais sentimentos não só marcam a relação do aluno com o objetivo de conhecimento, como também afetam a sua autoimagem, favorecendo a autonomia e fortalecendo a confiança em suas capacidades e decisões. (LEITE; TASSONI, 2006, p. 20).

Nesse sentido, percebíamos que ele buscava saber mais a respeito dos sonhos e expectativas dos discentes. O professor colocava-se como um auxiliador dentro desse processo de formação, a fim de construir uma relação fraternal entre eles.

Outro aspecto importante refere-se à didática utilizada para trabalhar os conteúdos. $\mathrm{O}$ professor não se orientava exclusivamente na estrutura proposta pelo livro didático, mas sim em realizar uma conciliação entre o que estava inserido no material didático e os elementos próprios da realidade vivenciada pelos discentes. Compartilhando dessa opinião, destaca-se Libâneo (1990), o autor traz a ideia de que o ensino somente é bem-sucedido quando os objetivos do professor coincidem com os objetivos de estudo do aluno e é praticado tendo em vista o desenvolvimento das 
suas forças intelectuais. Ensinar e aprender, pois, são duas facetas do mesmo processo, e que se realizam em torno das matérias de ensino, sob a direção do professor (LIBÂNEO, 1990, p. 54).

Um ponto interessante em se destacar, foi quando se discutiu a respeito de conceitos geográficos, o professor ofereceu um olhar mais aprofundado sobre o tema, contemplando os exames avaliativos no qual os alunos seriam submetidos. Contudo, ele buscava contextualizar o que foi abordado citando situações próprias da realidade dos discentes. Exemplos disso são: rios, formas de relevo e domínios morfoclimáticos, tudo isso contribui para estimular os alunos nos questionamentos. O que funcionava perfeitamente bem, estimulando os estudantes em seus questionamentos e colocações durante a aula.

Por fim, devido à pandemia causada pela COVID-19 e a decisão do CAp-COLUNI e da UFV de adotar o Ensino Remoto. Inicialmente, tivemos um certo pessimismo ao recebermos a notícia da volta às aulas, afinal estaríamos sendo privados da diversidade e da interação social, elementos tão presentes nas ambiências do colégio, uma vez que a educação constitui-se a partir da esfera coletiva, da pluralidade de ideias e do confronto entre os diferentes pontos de vista.

Contudo, buscamos considerar que estamos diante de um momento de enorme relevância influenciando profundamente a organização do processo educativo. Entendemos que a experiência é tudo aquilo que nos passa, o que nos acontece, o que nos toca (BONDÍA, 2002, p. 21). Por isso, passamos a considerar como imprescindível aproveitarmos esse momento e tecemos algumas considerações a respeito das aulas e suas peculiaridades em comparação ao modelo tradicional.

Em primeiro lugar, notamos que as aulas virtuais tendem a ser mais sintéticas, ou seja, o professor utiliza a maior parte do tempo para repassar o conteúdo proposto, tanto é que observamos que as classes tendem a ser ainda mais disciplinadas com relação à pontualidade. Em segundo, existe uma maior necessidade do docente intervir de forma frequente fazendo mais perguntas, a fim de evitar que a turma fique dispersa. Finalmente, percebemos que as listas de exercícios elaboradas por nós com a supervisão do professor-orientador, bem como as monitorias oferecidas em dias específicos no período da tarde desempenharam um papel importante na compreensão dos temas, contribuindo desse modo para mitigar os inúmeros prejuízos causados pela pandemia do coronavírus.

\section{CONSIDERAÇÕES FINAIS}

Tomando como base todas as discussões e vivências apresentadas nesse relato de experiência, convém destacar mais alguns aspectos que se fazem relevantes dentro dessa jornada na qual nos encontramos e que ainda está longe de acabar. 
Buscando concluir este trabalho, partimos de uma analogia entre o presencial e o remoto, ao qual precisamos nos remeter devido à pandemia da COVID-19, apresentando nossas considerações sobre todos esses processos aos quais nos abarcamos.

Neste contexto de pandemia, as diferenças do estágio remoto para o presencial fez com que nossa experiência se tornasse simultaneamente, mais fria, ocasionado pela falta de contato físico, e mais compreensível, uma vez que precisamos partir do ponto de vista que a realidade e o ensino dos alunos são ainda mais diferentes no contexto remoto do que eram no presencial.

Como futuros professores, entender e compreender essas diferenças são fundamentais na nossa jornada como estagiários. O estágio além de contribuir com o ganho teórico sobre a prática de ensino, também colaborou com o ganho de uma experiência com base em nossas próprias vivências, tornando o estagiário um elo entre a universidade e a escola e entre teoria e prática (SCALABRIN; MOLINARI, 2003, p. 4).

Enquanto estagiários por modalidade presencial tínhamos ao nosso dispor o contato direto com o professor orientador e os respectivos discentes. Cada estagiário acompanhava uma turma do terceiro ano do ensino médio e participava ativamente das três horas/aulas semanais que o professor ministrava. Normalmente acontecia semanalmente, uma reunião de planejamento sobre o conteúdo a ser administrado ou um fato relevante do cotidiano escolar.

Nessa mesma modalidade, era mais fácil ajudar os alunos em eventuais dúvidas e perceber suas reações em relação às atividades e conteúdos trabalhados, facilitando nossa interação, uma vez que estávamos mantendo relações interpessoais. Entretanto, na atual conjuntura, essas relações se dão totalmente online, mediadas pelas Tecnologias Digitais da Informação e da Comunicação.

No estágio remoto, percebemos o quanto as desigualdades socioeconômicas influenciaram a conectividade e a participação dos estudantes durante as atividades do COLUNI. Isto porque, entre os alunos pode ser um empecilho para que eles possam assistir às aulas. A dificuldade em se conectar com a internet dependendo dos seus respectivos locais de moradia, bem como as próprias instabilidades na rede que afetam todos que lidam diretamente com a rede mundial de computadores, gerou em alguns momentos, uma reduzida participação por turma e até mesmo uma desmotivação para continuar com os estudos. Além disso, a nossa vivência de campo com os discentes (elemento fundamental na Geografia) ficou completamente comprometida em razão das restrições sanitárias, fazendo com que tivéssemos uma relação efêmera, resumida em presenciar fotos de perfil dos alunos e no máximo escutar as suas vozes quando eles decidiam se manifestarem nos momentos síncronos das aulas virtuais ou de monitorias.

Em nossa visão, tendo como base todas essas experiências, entendemos que apesar das grandes perdas que esse momento nos traz, sejam elas didáticas (perda de conteúdos, experiências, 
campos, entre outros), culturais e sociais (como as quintas culturais os eventos colegiais ligados ao esporte, entre outros), ainda assim podemos identificar e compreender pontos positivos. Apesar de todos esses obstáculos, o CAp-COLUNI se mostra inovador e bem à frente da maioria de escolas de ensino médio do Brasil. O colégio conseguiu manter atividades síncronas através de softwares de ensino, fazendo com que haja o mínimo de relação direta entre estudantes, professores e estagiários.

Considerando esse momento de excepcionalidade em que estamos todos nós inseridos, acreditamos que tanto os estagiários, quanto os professores e discentes, estão utilizando da compreensão e da capacidade humana de se solidarizar para que consigamos tirar o melhor possível desse momento sem que haja um desgaste ainda maior ou até mesmo uma perda (pedagógica e social) que possa ser profundamente prejudicial para todos os envolvidos no âmbito educacional.

Sentimos falta de presenciar no dia a dia a correria e as conversas pelos corredores e áreas de convivência da escola. O presente relato, além de demonstrar como foram nossas experiências até então, busca socializar o nosso envolvimento e dedicação ao colégio e a todos os envolvidos nesse processo de construção do aprendizado.

Por fim, destacamos um ponto-chave que pode ajudar a diminuir os impactos do Ensino Remoto nas atividades pedagógicas de Geografia e demais conteúdos no CAp-COLUNI. Esse ponto seria o de oferecer um maior incentivo à aproximação entre a comunidade escolar e as famílias, visto que, a prática de ensino está se dando de forma remota, e, em grande maioria, nas casas dos alunos.

Nesse momento em que a escola passa a fazer parte do cotidiano doméstico dos alunos surge entre nós a reflexão de como esta poderia se aproximar ainda mais do ambiente familiar de forma construtiva e que contribua com o progresso da educação pública brasileira. Convém ressaltar ainda que, essa prática de aproximação deve ser algo permanente, estendendo-se para muito além da pandemia. Isso reforça a importância dos profissionais da educação no país, além de contribuir para a democratização da ciência na sociedade brasileira.

\section{REFERÊNCIAS}

BONDIA. J. L. Notas sobre a experiência e o saber da experiência. Revista Brasileira de Educação, n. 19. p. 20-28. jan-mar. 2002. Disponível em: https://www.scielo.br/pdf/ rbedu/n19/n19a02.pdf. Acesso em: 23 set. 2020.

CAP-COLUNI. Conheça o CAp-COLUNI. Disponível em: http://www.coluni.ufv.br/?page_id=5. Acesso em: 23 set. 2020.

CAP-COLUNI. Memória CAp- Coluni. Disponível em: https://memoriacoluni.ufv.br/cronologia/. Acesso em: 20 set. 2020. 
CAP-COLUNI. Projeto Político-Pedagógico - PPP. Disponível em: http://www.coluni.ufv.br/ wp-content/uploads/PPP.pdf. Acesso em: 15 set. 2020.

CAVAlCANTI, L. D. S. Ensinar Geografia para a Autonomia do Pensamento: O Desafio de Superar Dualismos pelo Pensamento Teórico Crítico. ANPEGE, Goiânia-GO, v. 7, n. 1, p. 193203, nov./2011. Disponível em: https://ojs.ufgd.edu.br/index.php/anpege/article/view/6563. Acesso em: 8 mar. 2021.

FOLHA DE SÃO PAULO. Veja o desempenho da sua escola no Enem 2019. Disponível em: https://www1.folha.uol.com.br/cotidiano/2020/07/veja-o-desempenho-da-sua-escola-no-enem 2019. shtml?utm_source=whatsapp\&utm_medium=social\&utm_campaign=compwa. Acesso em: 7 mar. 2021.

FREIRE, Paulo. Politica e Educação. 5. ed. São Paulo: Parma, 1992.

LEITE, S. A. S.; TASSONI, E. C. M. A afetividade em sala de aula: as condições de ensino e a mediação do professor. Disponível em https://www.fe.unicamp.br/alle/textos/SASL-AAfe tividadeemSaladeAula.pdf. Acesso em 2 de mai. de 2016.

UFJF-PEDAGOGIA. O Afeto que Educa: afetividade na aprendizagem. Disponível em: https: //www.ufjf.br/pedagogia/files/2017/12/O-AFETO-QUE-EDUCA.pdf. Acesso em: 8 mar. 2021.

MANFREDI, S. M. Metodologia do Ensino - diferentes concepções. Papirus, Campinas, v. 1, n. 13, p. 1-6, jun./1996. Disponível em: https://edisciplinas.usp.br/pluginfile.php/1974332/mod _resource/content/1/METODOLOGIA-DO-ENSINO-diferentes-concep\%C3\%A7\%C3\%B5es.pdf. Acesso em: 16 set. 2020.

SCALABRIN, I. C.; MOLINARI, A. M. C. A Importância da Prática do Estágio Supervisionado nas Licenciaturas. Revista Unar, Araras - SP, v. 7, n. 1, p. 1-12, dez./2013. Disponível em: http://revistaunar.com.br/cientifica/documentos/vol7_n1_2013/3_a_importancia_da_pratica_estagio .pdf. Acesso em: 15 set. 2020. 